TP Periodica Polytechnica Mechanical Engineering

60(2), pp. 103-112, 2016

DOI: 10.3311/PPme.8721

Creative Commons Attribution (i)

RESEARCH ARTICLE

\section{Characterization of poly(hydroxybutyr- ate-co-hydroxyvalerate)/ Sisal Fiber/Clay bio-composites Prepared by Casting Technique}

Jiratti Tengsuthiwat ${ }^{1}$, Pawinee Boonyasopon ${ }^{2}$, Rapeephun Dangtungee ${ }^{1,4}$, Suchart Siengchin ${ }^{1,3,4^{*}}$

Received 27 October 2015; accepted after revision 24 February 2016

\begin{abstract}
Poly(hydroxybutyrate-co-hydroxyvalerate)(PHBV) biocomposites containing of sisal fibers and clay particles were prepared by solution casting technique. Silane (Bis(triethoxysilylpropyl)tetrasulfide) treatment has been used to modify surface of sisal fiber and enhance the properties of related PHBV composites. The mechanical and thermal properties of the PHBV composites were determined in uniaxial tensile, dynamic mechanical analysis (DMA) and differential scanning calorimetry (DSC), respectively. The dispersion of the sisal fiber and clay in the PHBV was studied by scanning electron microscopy (SEM). All PHBV based composites were subject to water absorption. It was found that the tensile and storage modulus of PHBV/5 wt.\% sisal composites was improved by maximum $7 \%$ and $10 \%$ respectively. Treated silane of sisal fiber at 5 wt.\% was found to enhance tensile modulus by $12 \%$ as compared to the neat PHBV. In corporation of $3 \mathrm{wt} \%$ clay in PHBV matrix increased the tensile and storage modulus by $8 \%$ and $16 \%$ respectively, compared to the neat PHBV. Note that this feature was also confirmed by SEM. Moreover, water uptake and the diffusion coefficient of the PHBV composites systems studied was also calculated.
\end{abstract}

\footnotetext{
Keywords

Poly(hydroxybutyrate-co-hydroxyvalerate)(PHBV), silane, solution casting, Sisal, Composite

${ }^{1}$ Department of Mechanical and Process Engineering, The Sirindhorn International Thai-German Graduate School of Engineering (TGGS), King Mongkut's University of Technology North Bangkok, 1518 Pracharaj 1, Wongsawang Road, Bangsue, Bangkok 10800, Thailand

${ }^{2}$ Faculty of Architecture and Design, King Mongkut's University of Technology North Bangkok, 1518 Pracharaj 1, Wongsawang Road, Bangsue, Bangkok 10800, Thailand

${ }^{3}$ Natural Composite Research Group, King Mongkut's University of Technology North Bangkok, 1518 Pracharaj 1, Wongsawang Road, Bangsue, Bangkok 10800, Thailand

${ }^{4}$ Center of Innovation in Design and Engineering for Manufacturing (CoIDEM), King Mongkut's University of Technology North Bangkok, 1518 Pracharaj 1, Wongsawang Road, Bangsue, Bangkok 10800, Thailand

*Corresponding author, e-mail: suchart.s.pe@tggs-bangkok.org
}

\section{Introduction}

In the recent year, the aim to solve the environmental problem caused by the disposal of large volumes of conventional petroleum based plastics became to develop an increasing number of biodegradable polymer [1]. Biodegradable polymer-based packing materials are needed, especially those used for packing and disposable applications [2]. Among the various available biodegradable polymers such as PLA, PHB and PHBV have be used for bio-based polymer composites. Note that Poly(hydroxybutyrate-co-hydroxyvalerate (PHBV) is a Polyhydroxyalkanoates (PHAs) family widely used for an application in food packaging due to its good biocompatibility, biodegradability, however its widespread application was limited due to its narrow processing window and poor thermal and mechanical properties [3-5]. It was recognized earlier that the natural fibers reinforcement of these biodegradable polymers might be considered an effective way to improve of these mechanical properties. Natural fibers exhibit advantageous properties as reinforcement for composites. Moreover, the density of fibers is low which can be great benefit also for the lightweight construction. The lightweight polymer composites which may compete with traditional composites in various application fields of an example in automotive industries [6]. Usually, the preparation technique of the polymer composites such as in-situ polymerization, melt compounding and solution techniques, has a strong influence on the final properties of resulted composites. Major benefit of the solution technique, covering also the casting solution method is widely used for dispersion of the particles and modified fiber and polymer matrix. K.C. Reis et al. [7] demonstrated that PHBV with maize starch biocomposites can be produced using solution casting method. The result showed that tensile modulus of PHB-HV/maize starch composites decreased with an increase the maize starch content and tensile strength also decreased. The significant decrease in tensile properties could be the low interfacial interaction between the components of the blend which lead to mechanical rupture at the blend interface. HouYong Yu et al. [2] reported on PHBV reinforced with PHBVgrafted multi-walled carbon nanotubes (PHBV-g-MWCNTs) 
were prepared by solution casting method. Tensile strength and tensile modulus of nanocomposites film containing $7 \mathrm{wt} . \%$ PHBV-g-MWCNTs was improved by $88 \%$ and $172 \%$ respectively, compared to the neat PHBV. These improvements depend on good dispersion of PHBV-g-MWCNTs within the polymer matrix and enhanced interfacial interaction due to the compatibility of the two phase.

The aims of this work were demonstrate the feasibility of the fabrication of PHBV film reinforced with sisal fiber unmodified and modified surface with different sisal volume fractions and clay particles content by using solution casting method and compare the mechanical properties, dynamic mechanical properties, thermal properties and water absorption with the neat PHBV. The dispersion of sisal fiber and interfacial interface between sisal and PHBV was assessed by scanning electron microscopy (SEM).

\section{Materials and Methods \\ 2.1 Materials}

PHBV in a fine powder form was provided by Ningbo Tianan Biologic Material Co.,Ltd., Ningbo, China and used as matrix. The melt flow index (MFI) of PHBV was $4.35 \mathrm{~g} / 10 \mathrm{~min}$ $\left(190{ }^{\circ} \mathrm{C}, 2.16 \mathrm{~kg}\right)$, the density was $1.25 \mathrm{~g} / \mathrm{cm}^{3}$ and the molecular weight was $340,000 \mathrm{~g} / \mathrm{mol}$. Sisal fiber were supplied by Hupkapong Agricultural Co-operative Ltd., Hupkapong Female Agricultural Cooperative Village, Phetchaburi, Thailand. Silane (bis(triethoxysilylpropyl)tetrasulfide) was purchased from Nanjing Capatue Chemical Co.,Ltd., China and Clay were supplied by Polymer Innovation Co. Ltd., Nonthaburi, Thailand.

\subsection{Methods}

\subsubsection{Fabrication of composites}

Prior to the PHBV/sisal fiber processing, the length of sisal fibers was cut for $0.25 \mathrm{~mm}$. To release the moisture, PHBV powder and sisal fiber were dried at $60{ }^{\circ} \mathrm{C}$ for $24 \mathrm{hr}$. Then, PHBV powder was dissolved in chloroform solutions. For $\mathrm{PHBV} /$ sisal fiber films were prepared by solution-casting technique. $\mathrm{PHBV} /$ sisal with different fiber volume fractions were produced at $60{ }^{\circ} \mathrm{C}$ for 40 minutes under constant stirring on magnetic stirrer-hotplate. The PHBV/sisal films $(90-100 \mu \mathrm{m})$ were obtained by pouring the solution onto the glass slide as a casting surface, allowing the solvent to evaporate at room temperature overnight. For the preparation of PHBV/clay films, a predetermined amount of clay was dispersed in a solvent by sonication for $1 \mathrm{hr}$. at room temperature. The nanoclay solutions were mixed with the PHBV solution and stirred for 40 minutes, then casted onto the glass slide. The composition of PHBV composites were listed in Table 1.

\subsubsection{Fiber treatment}

Prior to fiber treatment, the untreated sisal fibers were washed with water, and then dried in an oven at $60{ }^{\circ} \mathrm{C}$ for
2 hours. A solution of 3 vol.\% and 5 vol.\% of silane coupling agent (bis(triethoxysilylpropyl)tetrasulfide) was prepared in acetone. Sisal fibers were immersed in the solution for 24 hours under constant stirring on magnetic stirrer-hotplate. The treatment of sisal fibers included removal from the solution and dried in the oven at $60{ }^{\circ} \mathrm{C}$ for 24 hours.

Table 1 Composition of different materials

\begin{tabular}{lllll}
\hline Materials & $\begin{array}{l}\text { Matrix } \\
(\text { wt. } \%)\end{array}$ & $\begin{array}{l}\text { Sisal fiber } \\
(\text { wt.\%) }\end{array}$ & Clay (wt.\%) & $\begin{array}{l}\text { Silane } \\
(\text { vol.\%) }\end{array}$ \\
\hline PHBV & 100 & - & - & - \\
PHBV/Sisal & 95 & 5 & - & - \\
PHBV/Sisal & 90 & 10 & - & - \\
PHBV/Sisal & 80 & 20 & - & - \\
PHBV/Silane/Sisal & 95 & 5 & - & 3 \\
PHBV/Silane/Sisal & 95 & 5 & - & 5 \\
PHBV/Clay & 97 & - & 3 & - \\
PHBV/Clay & 95 & - & 5 & - \\
PHBV/Clay & 90 & - & 10 & - \\
PHBV/Sisal/Clay & 92 & 5 & 3 & \\
\hline
\end{tabular}

\subsubsection{Mechanical properties}

Tensile properties were studied by using a Testometric M50025AT, The Testometric Company Ltd., UK, with a load cell of $100 \mathrm{~N}$. Ten sample strips $(5 \mathrm{~mm} \times 70 \mathrm{~mm})$ of each type were cut and clamped between two tensile grips at deformation rate $50 \mathrm{~mm} / \mathrm{min}$ with initial distance between the grips of $50 \mathrm{~mm}$.

Dynamic mechanical analysis (DMA) was used in tension mode on a DMA 1 METTLER TOLEDO, METTLER TOLEDO (Thailand) Ltd., at $1 \mathrm{~Hz}$ to examine thermal dynamic properties of the composites films. DMA samples was rectangular $5 \mathrm{~mm} \times 25 \mathrm{~mm}$. Temperature was swept from $25^{\circ} \mathrm{C}$ to $140{ }^{\circ} \mathrm{C}$ at $5^{\circ} \mathrm{C} / \mathrm{min}$ heating rate with amplitude $10 \mu \mathrm{m}$.

\subsubsection{Thermal properties}

Differential scanning calorimetry (DSC) was used to study the melting temperature $\left(T_{m}\right)$, crystallization temperature $\left(T_{c}\right)$, enthalpy of melting $\left(\Delta H_{m}\right)$ and cold crystallization enthalpy $\left(\Delta H_{c}\right)$ by using a DSC 1 METTLER TOLEDO, METTLER TOLEDO (Thailand) Ltd. All samples were placed in a sealed aluminum pan under a $50 \mathrm{ml} / \mathrm{min}$ nitrogen flow. The samples were first heated from 30 to $200{ }^{\circ} \mathrm{C}$ at a rate of $50{ }^{\circ} \mathrm{C} / \mathrm{min}$ and then kept isothermal for $3 \mathrm{~min}$ to remove previous thermal history. Then samples were cooled down to $0{ }^{\circ} \mathrm{C}$ at a rate of $10{ }^{\circ} \mathrm{C} / \mathrm{min}$ before being reheated to $200{ }^{\circ} \mathrm{C}$ at a rate of $10^{\circ} \mathrm{C}$.

\subsubsection{Water absorption}

Water absorption of PHBV composites was carried out according to ASTM D570-98 standard test method. The 
PHBV composites were cut into specimens rectangular $(25 \times$ $60 \times 0.1 \mathrm{~mm}^{3}$ ) and then immersed in a distill water bath over a period of 300 hours. The percentage gain at any time $\left(\mathrm{M}_{t}\right)$ was calculated from this equation:

$$
M_{t}=\left(\frac{W_{w}-W_{d}}{W_{w}}\right) \times 100 \%
$$

where, $W_{d}$ and $W_{w}$ denote the initial weight of material and weight of material after exposure to water absorption, respectively.

\subsubsection{Water diffusion coefficient}

The average diffusion coefficient $(D)$ measures the rate of moisture diffusion through all faces of the film. For each film, the maximum percent of moisture uptake $M_{m}$, the initial slope of the line of the moisture content versus square root of time graphs and the film thickness, $h$, were calculated by using the following equation:

$$
D=\pi\left(\frac{h}{4 M_{m}}\right)^{2}\left(\frac{M_{2}-M_{1}}{\sqrt{t_{2}}-\sqrt{t_{1}}}\right)^{2}
$$

\subsubsection{Scanning electron microscope}

Scanning electron microscope (SEM, Hitachi model T3000, Japan) images of the fracture surface of PHBV composites film were obtained by using a low-vacuum operated at $15 \mathrm{kV}$.

\section{Result and discussions}

\subsection{Tensile Properties}

The tensile modulus and tensile strength data of PHBV composites as a function of sisal fiber contents are shown in the Table 2, respectively. One can see in this table that the tensile modulus of PHBV composites improved with additional of sisal fiber contents. Especially, at 5 wt.\% of sisal fiber loading, the tensile modulus increased $8 \%$ compared to the neat PHBV. A possible explanation of the increased of PHBV composites can be ascribed to uniform dispersion of sisal fibers in PHBV, which lead to the distribution and transfer of stress from matrix to sisal fiber. Note that SEM image in Fig. 7(a) indicated that 5 wt.\% sisal fibers were uniformly dispersed in PHBV matrix. However, the tensile modulus in case of the $20 \mathrm{wt} . \%$, sisal fiber composite slightly decreased. As reported by Sanjeev et al. [8]. Tensile properties of natural fiber composites influenced on many factors such as length, distribution, orientation of fiber and their interfacial bond strength with matrix. One can clearly recognize that short sisal fiber-reinforced PHBV composites can be improved tensile modulus [9]. Whereas, the tensile strength of PHBV composites decreased with addition of sisal fiber. This could be attributed to the related high fiber contents and poor adhesion between sisal fiber and matrix which lead to premature fracture.

It has been reported that adding silane coupling agent improved an interfacial interaction of between fiber and matrix [10]. This is accordance with our tensile test observation of $\mathrm{PHBV} / \mathrm{sisal}$ composites system as shown in Table 2, the addition of 5 wt. $\%$ of silane-treated sisal in PHBV matrix ( 5 vol. $\%$ of silane) increased the tensile modulus by $5 \%$ compared to untreated one. Note that silane reduced a number of cellulose hydroxyl groups in the fiber matrix interface. In the presence of moisture, hydrolysable alkoxy group leads to the formation of silanols. The silanols reacted with the hydroxyl group of the fiber and then formed stable covalent bonds to the cell wall that were chemisorbed onto the fiber surface [11]. Whereas, the tensile strength of PHBV/treated sisal did not significantly improved. This could be attributed to good adhesion between treated sisal fiber and PHBV (cf. Fig. 8).

Tensile modulus and tensile strength data of PHBV composites and hybrid with addition of clay particles are shown in Table 2. It can be seen that the tensile modulus of PHBV/clay composites increased with clay loading. Especially, the tensile modulus of 3 wt.\% clay loading PHBV composite increased $8 \%$ compared to the neat PHBV. However, addition of clay particles reduced the tensile strength compared to the neat PHBV. A decrease of tensile strength can be attributed to the incomplete dispersion of clay agglomerate into the PHBV matrix (cf. Fig. 10). Moreover, the tensile modulus of $\mathrm{PHBV} /$ sisal/clay hybrid composites increased by $18 \%$ compared to the neat PHBV.

Table 2 Tensile properties of PHBV composites

\begin{tabular}{|c|c|c|}
\hline & $\begin{array}{l}\text { Tensile strength } \\
(\mathrm{MPa})\end{array}$ & $\begin{array}{l}\text { Tensile modulus } \\
(\mathrm{MPa})\end{array}$ \\
\hline PHBV & 30.7 & 1403 \\
\hline 5 wt. \% Sisal & 23.6 & 1501 \\
\hline 10 wt. \% Sisal & 22.2 & 1419 \\
\hline 20 wt. $\%$ Sisal & 20.7 & 1394 \\
\hline 5 wt. $\%$ Sisal/Silane $3 \%$ & 23.5 & 1560 \\
\hline 5 wt. $\%$ Sisal/Silane $5 \%$ & 23.4 & 1569 \\
\hline 3 wt. $\%$ Clay & 27.3 & 1506 \\
\hline 5 wt. $\%$ Clay & 25.4 & 1441 \\
\hline 10 wt. \% Clay & 23.1 & 1414 \\
\hline 5 wt. $\%$ Sisal $/ 3$ wt. $\%$ Clay & 25.3 & 1651 \\
\hline
\end{tabular}
and its hybrid composites system study.

\subsection{Dynamic mechanical properties}

Dynamic mechanical analysis (DMA) was used to investigate the viscoelastic properties of PHBV and related composites system studied. The storage modulus $\left(E^{\prime}\right)$ of all the samples were observed to decline with increasing temperature range $\left(25^{\circ} \mathrm{C}\right.$ to $\left.140{ }^{\circ} \mathrm{C}\right)$, as shown in Fig. 1a and b. One can notice that the storage modulus of all sisal/PHBV composites 
was higher than that of the neat PHBV at whole investigated temperatures. For the storage modulus of $5 \mathrm{wt} . \%$ sisal fiber/ PHBV composite increased approximately $10 \%$ compared to the neat PHBV. This can well explained by the reinforcing effect of the natural fibers leading to increased stiffness (cf. Fig. 1a). It is interesting to note that the storage modulus increased remarkably with $20 \%$ sisal reinforced PHBV at the high temperature range $70{ }^{\circ} \mathrm{C}$ onward. The incorporation of clay nanoparticles into $\mathrm{PHBV}$ and $\mathrm{PHBV} / \mathrm{sisal}$ resulted in a stiffness enchantment at the whole temperature range (cf. Fig. 1b). It is clear from Fig. $1 \mathrm{~b}$ that the storage modulus can be improved with increasing clay contents. This indicated the character of the nanoparticles leading to increased stiffness [12]. However, poor adhesion of $20 \mathrm{wt} \%$ clay agglomeration in the PHBV matrix acted as stress concentrations and followed crack in interfacial debonding which accompanied by a decrease in storage modulus. The reinforcing effect of the hybrid composites contacting clay and sisal fiber indicated an increase in the stiffness at the whole temperature range by approximately $20 \%$, compared to the neat PHBV.

\subsection{Water absorption}

The water absorption of PHBV containing different amounts of sisal fiber composites as a function of time demonstrate in Fig. 2. One can recognize that the water sorption behavior was considered depend on the sisal contents. The neat PHBV recorded water uptake value at $0.8 \%$ after subject to water absorption at $300 \mathrm{hr}$. The $\mathrm{PHBV} /$ sisal composites exhibited remarkably large amount of water absorption. Note that, the water absorption of $20 \mathrm{wt} . \%$ sisal fiber/PHBV composite for the first $24 \mathrm{hr}$ and $300 \mathrm{hr}$ increased by $3.6 \%$ and $4.2 \%$ respectively compared with the neat PHBV. This can be explained by the chemical nature of cellulose contents in sisal fiber. The water absorption of $\mathrm{PHBV} /$ treated sisal composites was shown in Fig. 3. It is interesting to note that water absorption decreased for PHBV/treated sisal composites. This was attributed to the hydrophilic properties of sisal fibers reduced with the incorporation of silane, which improved compatibility and adhesion of PHBV/sisal composites. It is also in accordance with previous report [9]. Figure 4 depicts the water absorption behavior of PHBV/clay nanoparticles composites and hybrid systems.



Fig. 1 Storage modulus, E‘ PHBV/sisal fiber (a) and PHBV/Clay and hybrid composites (b) 


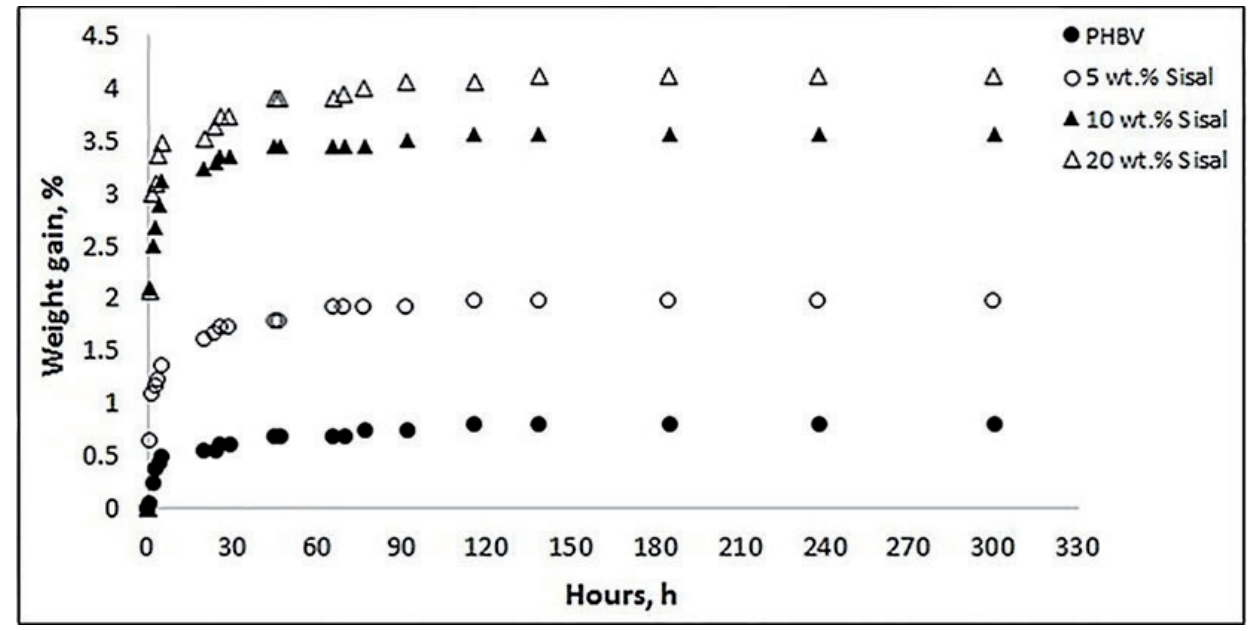

Fig. 2 Water absorption of different sisal fiber contents

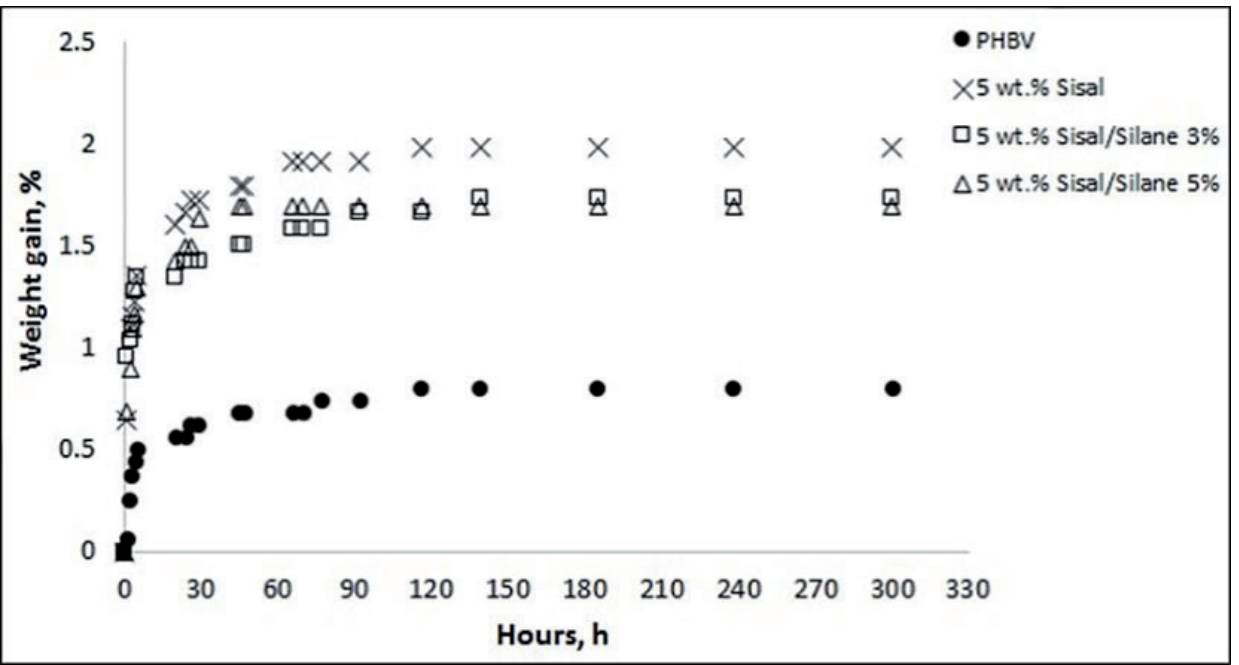

Fig. 3 Water absorption of treated and untreated sisal fiber

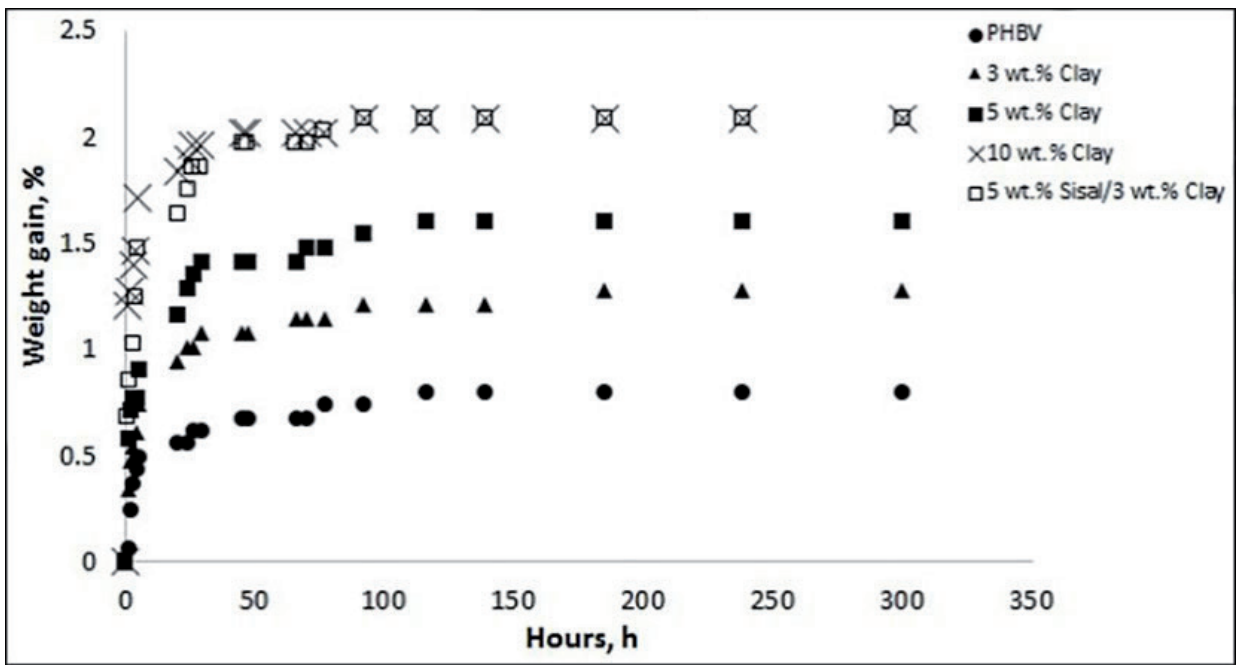

Fig. 4 Water absorption of PHBV/Clay composites and hybrid systems

The water absorption of PHBV/clay composites increased with increasing clay contents. For the $10 \mathrm{wt} . \%$ of clay/PHBV composite recorded water absorption value at $2.1 \%$ upon $300 \mathrm{hr}$. Furthermore, the incorporation of clay in the PHBV/sisal composites slightly increased water absorption. This is attributed to the hydrophilic of clay nanoparticles. Fick's law in Eq. (2) is adopted to calculate the diffusion coefficient $(D)$ of water absorption value. It is well resolved that there is a fair agreement between the water uptake and those calculated by Fick's law. The calculation of diffusion coefficient is shown in Table 3. 
The $D$ value of PHBV/sisal composites decreased with addition of clay nanoparticles. This may be liked to an incorporation of silane and clay nanoparticles. A similar trend has been reported for poly(lactic acid)/chitosan composites that the improvement of compatibility and interfacial bonding of PLA/chitosan blends can be reduced the water transmission rate [13]. For the PHBV composites that contain 3 wt.\% clay, for example, the diffusion coefficient was reduced by 5 times compared to the neat PHBV. The results suggested that $D$ value may be sensitive to the nanoparticles' barrier effect. It has also been observed by Becker et al. [14] that these nanoparticles reacted with water, leading to a decrease in the rate of diffusion. Moreover, it is an open issue whether there is a correlation between the diffusion and dispersion of incorporation of silane and clay particles. However, this aspect was not addressed in this work.

Table 3 Calculated the diffusion coefficient $(D)$

\begin{tabular}{lll}
\hline & $D\left(\mathrm{~mm}^{2} / \mathrm{h}\right)$ & $R^{2}$ \\
\hline PHBV & $5.443 \mathrm{E}-05$ & 0.91 \\
5 wt.\% Sisal & $3.385 \mathrm{E}-03$ & 0.97 \\
10 wt.\% Sisal & $4.869 \mathrm{E}-02$ & 0.93 \\
20 wt.\% Sisal & $9.697 \mathrm{E}-02$ & 0.95 \\
5 wt.\% Sisal/Silane 3\% & $1.410 \mathrm{E}-03$ & 0.93 \\
5 wt.\% Sisal/Silane 5 \% & $1.178 \mathrm{E}-03$ & 0.99 \\
3 wt.\% Clay & $2.848 \mathrm{E}-04$ & 0.99 \\
5 wt.\% Clay & $6.737 \mathrm{E}-04$ & 0.93 \\
10 wt.\% Clay & $4.990 \mathrm{E}-03$ & 0.91 \\
5 wt.\% Sisal/3 wt.\% Clay & $3.690 \mathrm{E}-03$ & 0.99 \\
\hline
\end{tabular}

\subsection{DSC properties}

DSC is an important method to study the effect of fiber contents,-treatment and nanoparticles on a crystallinity of PHBV. The incorporation of sisal and silane treated-fiber had a significantly effect on the overall crystallinity of PHBV in the related systems (cf. Fig. 5 a-b). DSC data was summarized in Fig. 5 a-b and Table 4. Addition of sisal fiber disturbed the crystallinity of PHBV. The enthalpy $\left(\Delta H_{m}\right)$ of PHBV decreased with increasing sisal and silane contents can be observed in Fig. 5a when compared with the neat PHBV. One can recognize that the degree of crystallization was affected by the fiber contents. However, the sisal fiber does not influence much the melting point. It can be seen also in Figs. 6 a-b that the incorporation of clay strongly enhanced the crystallinity of PHBV, due to the clay particles played a role of nucleating agent and may have increased the nucleating density of the PHBV matrix $[15,16]$. The neat PHBV resulted in a developing the crystal growth, located at about $83{ }^{\circ} \mathrm{C}$ for representing the crystallization temperature $\left(T_{c}\right)$ of the PHBV. At $10 \mathrm{wt} . \%$ of nanoclay, the $T_{c}$ increased from $83.7{ }^{\circ} \mathrm{C}$ to $88.76{ }^{\circ} \mathrm{C}$, compared to the neat PHBV (cf. Table 4). One can notice that the incorporation of clay and sisal fiber increased the intensity of crystallization process. Moreover, the crystallization temperature peak shifted toward higher temperatures, due to the silane treated fibers indicated an improvement of segmental motion in the boundary amorphous layers of the crystals which disordered in a crystalline phase of PHBV.

Table 4 Thermal characteristics of the PHBV/sisal fiber, PHBV/Clay and its hybrid composites

\begin{tabular}{lllll}
\hline & $T_{m}\left({ }^{\circ} \mathrm{C}\right)$ & $\Delta H_{m}(\mathrm{~J} / \mathrm{g})$ & $T_{c}\left({ }^{\circ} \mathrm{C}\right)$ & $\Delta H_{c}(\mathrm{~J} / \mathrm{g})$ \\
\hline PHBV & 169.2 & 104.1 & 83.7 & 87.2 \\
5 wt.\% Sisal & 170.4 & 105.2 & 92.4 & 80.7 \\
10 wt.\% Sisal & 170.2 & 97.7 & 93.6 & 69.3 \\
20 wt.\% Sisal & 169.7 & 83.8 & 95.6 & 70.3 \\
5 wt.\% Sisal/Silane 3\% & 170.3 & 93.7 & 94.5 & 75.7 \\
5 wt.\% Sisal/Silane 5\% & 169.7 & 93.6 & 96.2 & 78.5 \\
3 wt.\% Clay & 169.6 & 121.4 & 85.6 & 84.9 \\
5 wt.\% Clay & 167.3 & 118.7 & 87.4 & 85 \\
10 wt.\% Clay & 168.7 & 108.3 & 88.8 & 87.8 \\
5 wt.\% Sisal/3 wt.\% Clay & 167.9 & 105 & 91.8 & 86.9 \\
\hline
\end{tabular}

\subsection{Morphology}

SEM images of the surface and fracture cross section for the PHBV film composites can be seen in Fig. 7a-b which can observe the overview of PHBV composites system studied. One can see that most of sisal fibers were pulled out and also uniform dispersed in the PHBV matrix (cf. Fig. 7a). Note that the sisal fiber were in the form of a single fiber and indicated that fiber had not been damaged after stirring process. Some gaps can be observed in Fig. 8a, this was attributed to the incompatibility between sisal fibers and PHBV matrix. The formed gaps mainly due to the hydrophilic characteristic of the sisal fibers and high reactivity of the PHBV with moisture. This incompatibility of fiber/matrix interfaces reduced the mechanical properties as in above results. Moreover, addition of silane-treated sisal fiber was well embedded in the PHBV matrix as show in Fig. 8b, which increased an interfacial adhesion of the sisal fiber/PHBV composites. The stiffness properties of PHBV film composites can be enhanced due to the development of debonding PHBV molecule chains and sisal fiber pull-out. To confirm the modified sisal fiber with silane, the SEM sample was subject to energy dispersive X-ray spectrometer (EDAX) analysis. Figure 9 demonstrates EDAX images of the corresponding PHBV-modified sisal fiber. To select different spots of sample, an elemental analysis was performed. EDAX revealed the major constituents of silane. This was indicated that the sisal fiber was coated by silane. Moreover, the difference amount of silane did not significantly effect. 


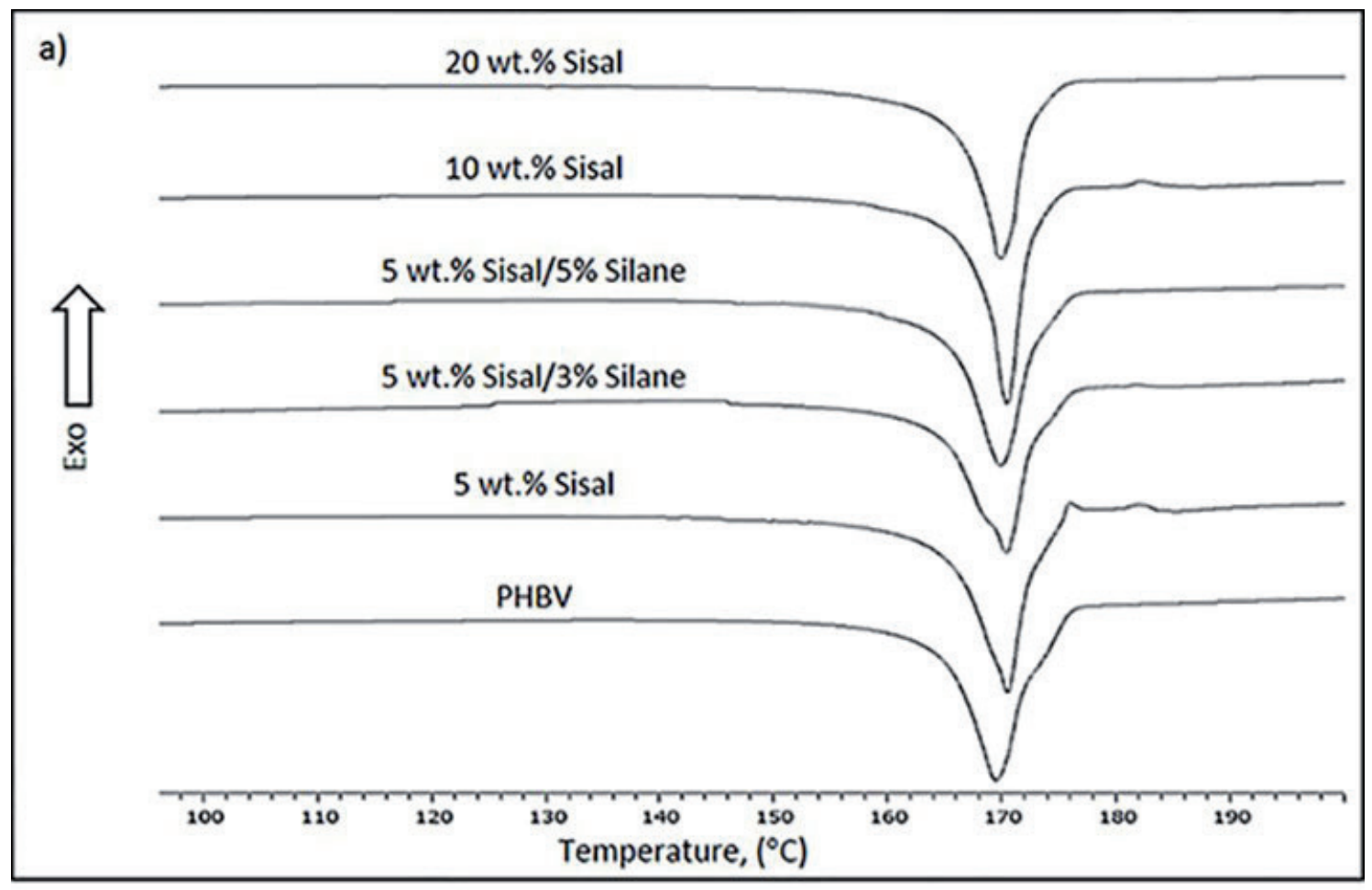

Fig. 5a Melting curve of PHBV composites treated and untreated with different sisal fiber contents

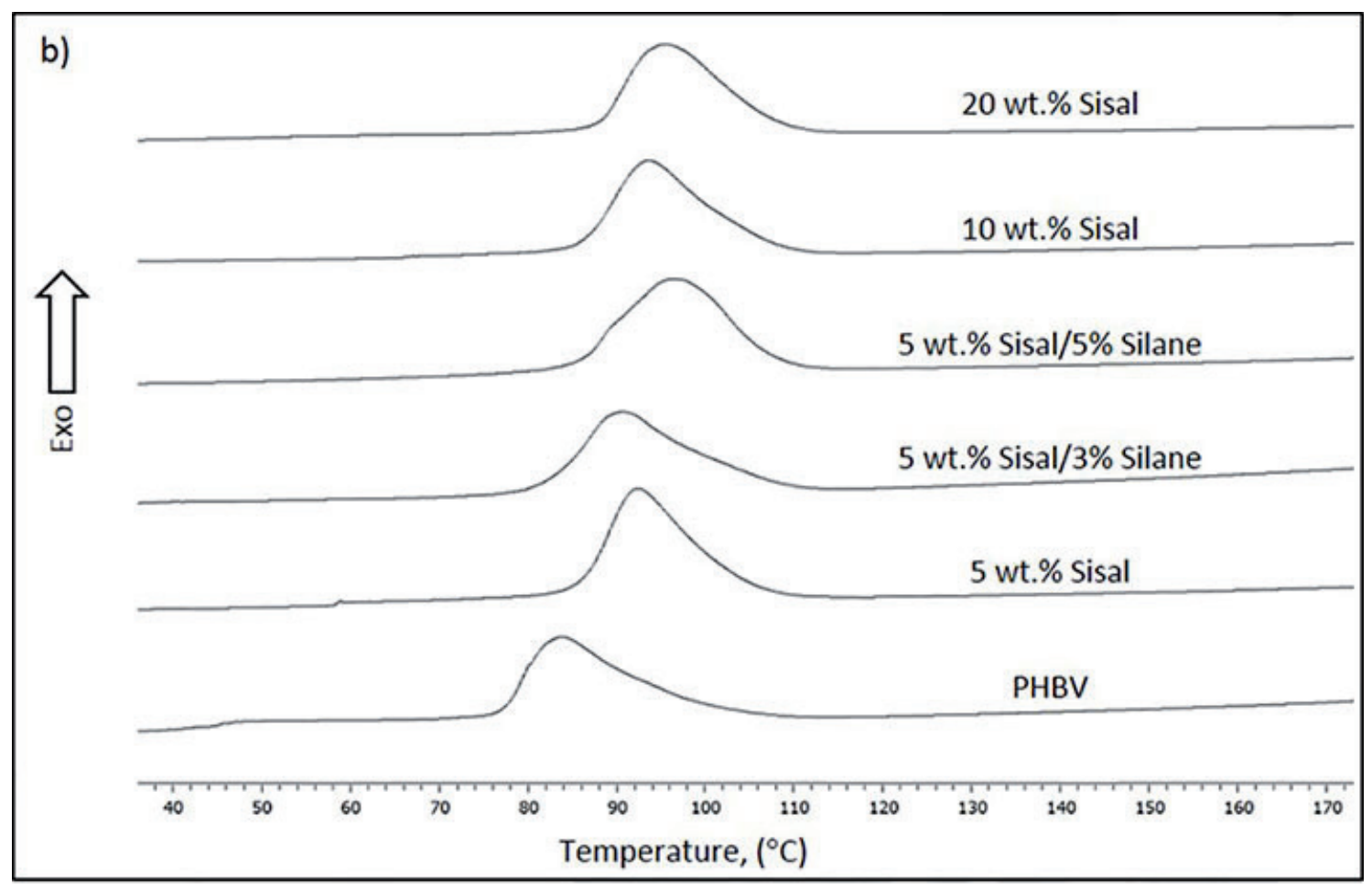

Fig. 5b Crystallization curve of PHBV composites treated and untreated with different sisal fiber contents 


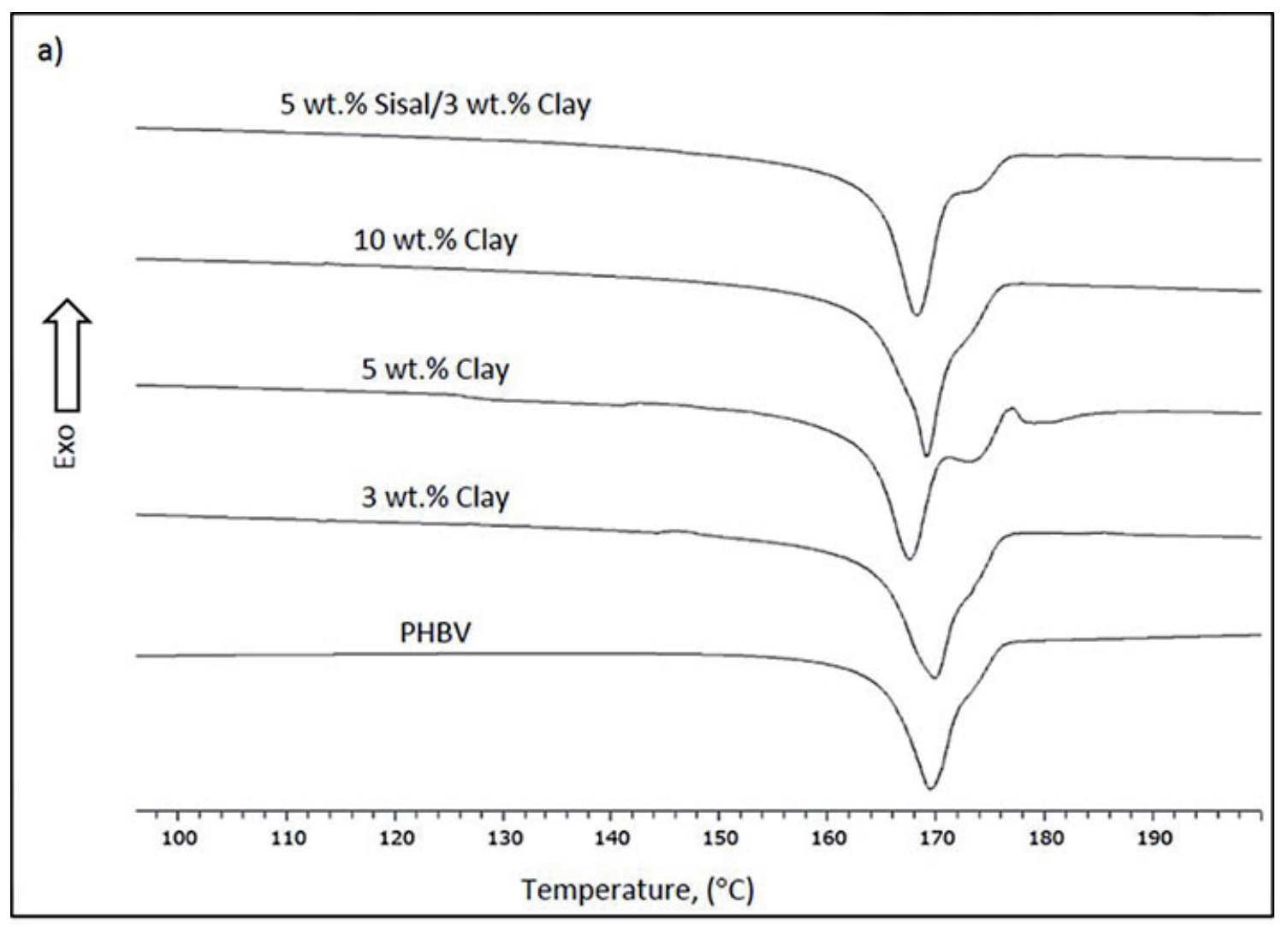

Fig. 6a Melting curve of PHBV/Clay composites and hybrid system

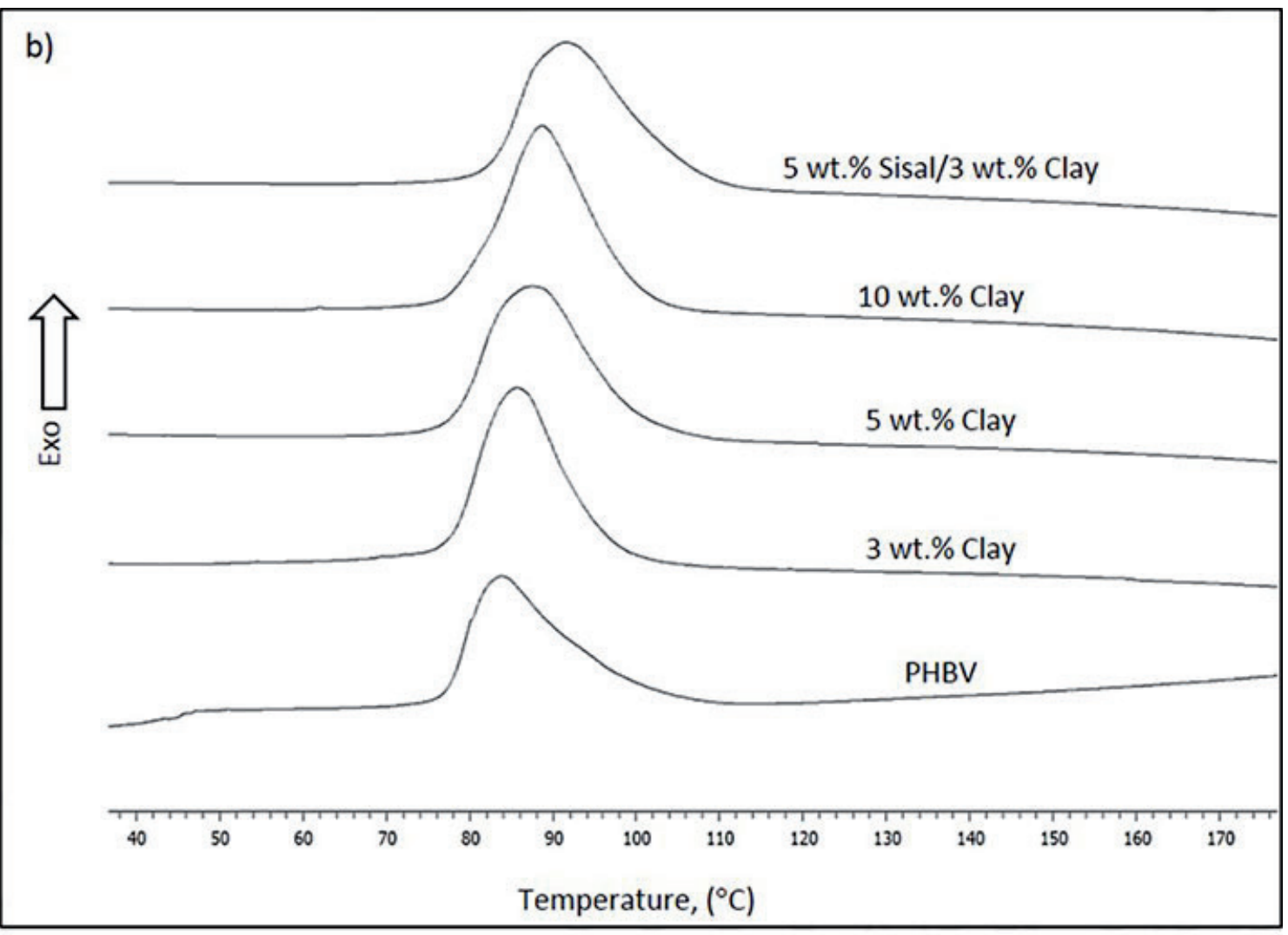

Fig. 6b Crystallization curve of PHBV/Clay composites and hybrid system 
a)

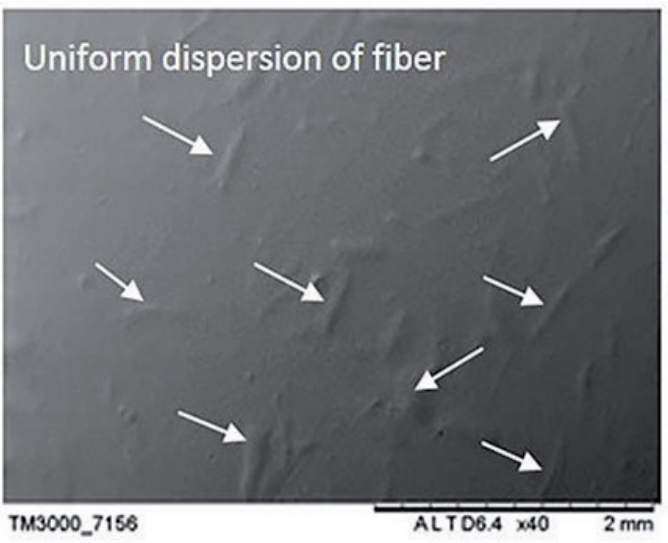

b)

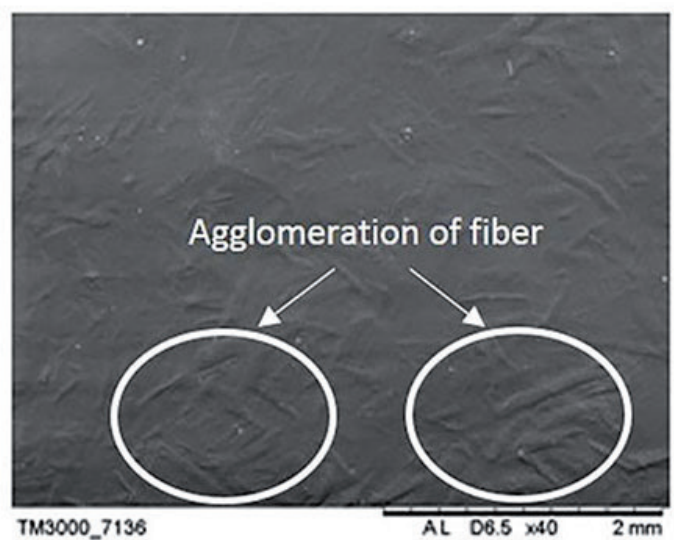

Fig. 7 SEM images on surface of PHBV with 5 wt.\% sisal fiber (a) and 20 wt.\% sisal fiber (b).

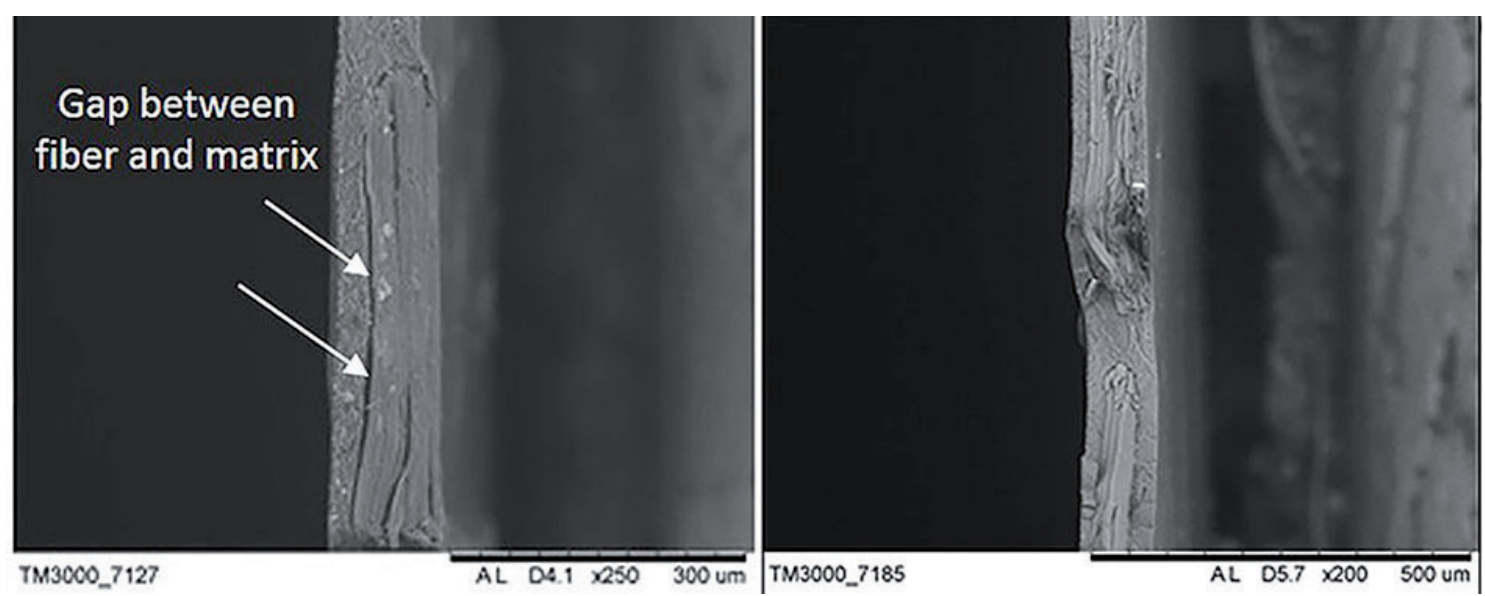

Fig. 8 SEM images of fracture cross section surface of 5 wt.\% (a) and PHBV with 5 wt.\% modified sisal fiber composites at $5 \%$ silane (b)

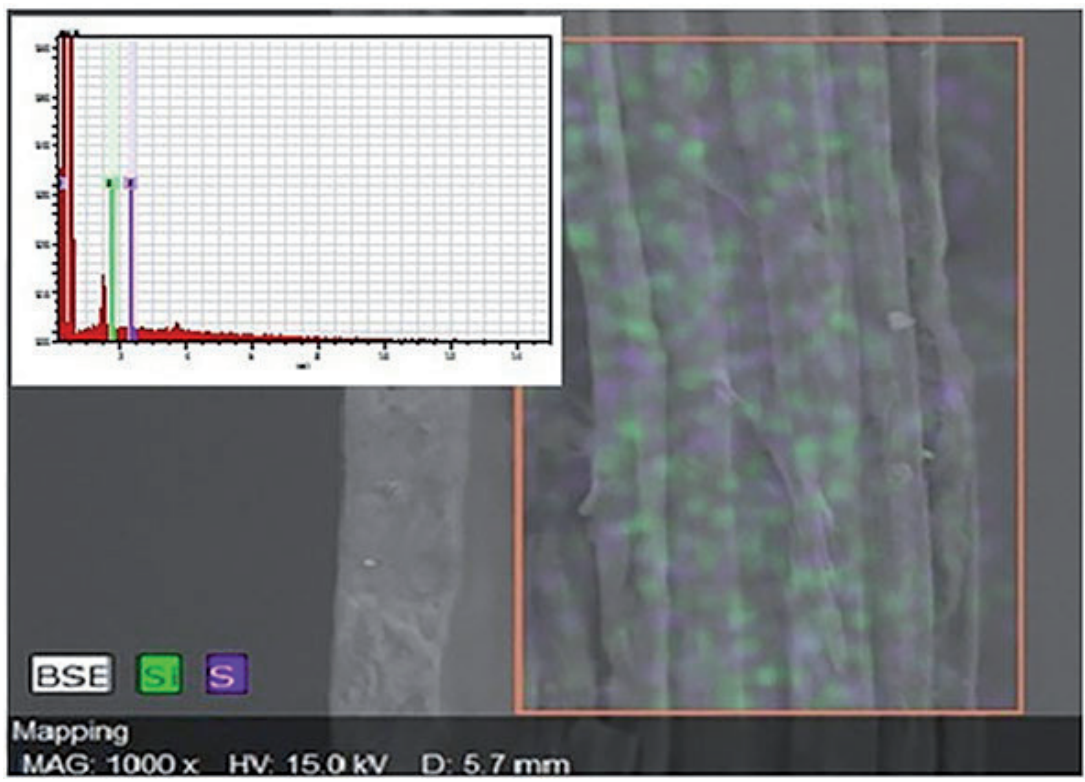

Fig. 9 EDAX image of surface of the modified sisal fiber/PHBV composites at $3 \%$ silane. 
For the PHBV/clay composites, it was also clear in Fig. 10 that the clay particles agglomeration dispersed in the PHBV matrix. Note that the energy absorption reduced when a crack grew through the clay agglomeration.

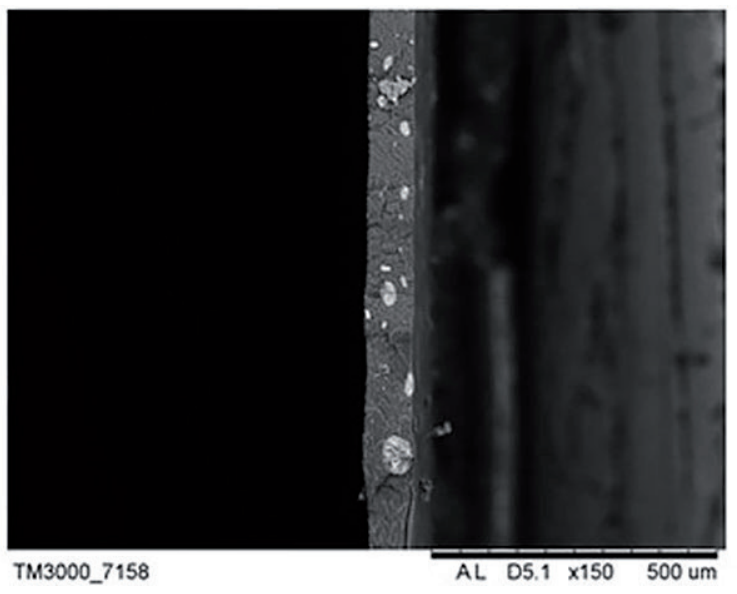

Fig. 10 SEM image of PHBV/ 3 wt.\% clay composites

\section{Conclusions}

The objective of this work was to study the effect of proportions of sisal fibers-reinforced PHBV composites and hybrid with addition of clay nanoparticles on mechanical, thermal properties and morphology. The preliminary results showed that, the highest value of tensile modulus was found at PHBV with 5 wt.\% sisal fiber which increased by $8 \%$ compared with the neat PHBV. The dispersion of sisal fiber was well and still aligned in PHBV matrix as shown in SEM images. The dynamic mechanical properties of PHBV-reinforced sisal fiber increased at any proportion of sisal fiber compared to the neat PHBV. Furthermore, the tensile modulus of $5 \mathrm{wt} . \%$ treated sisal fiber was also enhanced approx. $4 \%$ compared with untreated one. Incorporation of clay nanoparticles in PHBV matrix and $\mathrm{PHBV} /$ sisal fiber hybrid composites resulted in a considerable increase of the tensile modulus and storage modulus. The reduction in tensile strength was attributed to the agglomeration of clay in the PHBV hybrid composites. The DSC thermograms were demonstrated that sisal fiber acted as nucleating agent. The high content of sisal fiber may have been increased the nucleating density of the PHBV matrix. Addition of silane treated-fiber played an important role in improving the crystallinity of $\mathrm{PHBV} /$ sisal fiber composites. The incorporation of nanoclay influenced on crystallization temperature $\left(T_{c}\right)$. For 3 wt. $\%$ of nanoclay/PHBV composite, the $T_{c}$ increased from $83.7^{\circ} \mathrm{C}$ to $85.89^{\circ} \mathrm{C}$ compared to the neat PHBV.

\section{Acknowledgements}

The authors are grateful to Natural Composites Research Group (NCR) for laboratory support. This work was financially supported by the Higher Education Commission under the grant agreement KMUTNB-NRU-58-15. Part of this work is also linked with the Royal Golden Jubilee Ph.D. Program.

\section{References}

[1] Zhang, Q., Liu, Q., Mark, J. E., Noda, I. "A novel biodegradable nanocomposite based on poly (3-hydroxybutyrate-co-3-hydroxyhexanoate) and silylated kaolinite/silica core-shell nanoparticles." Applied Clay Science. 46(1), pp. 51-56. 2009. DOI: 10.1016/j.clay.2009.07.008

[2] Hou-Yung, Y., Zong-Yi, Q., Bin, S., Xiao-Gang, Y., Ju-Ming, Y. "Reinforcement of transparent poly(3-hydroxybutyrate-co-3-hydroxyvalerate) by incorporation of functionalized carbon nanotubes as a novel bionanocomposite for food packaging." Composites Science and Technology. 94, pp. 96-104. 2014. DOI: 10.1016/j.compscitech.2014.01.018

[3] Chen, G. G.-Q. "Plastics from Bacteria: Natural Functions and Applications." Springer Science \& Business Media. 2010. DOI: 10.1007/978-3-642-03287-5

[4] Rogers, M. E., Long, T. E. "Synthetic Methods in Step-Growth Polymers." John Wiley \& Sons. 2003. DOI: 10.1002/0471220523

[5] Bugnicourt, E., Cinelli, P., Lazzeri, A., Alvarez, V. "Polyhydroxyalkanoate (PHA): Review of synthesis, characteristics, processing and potential applications in packaging." Express Polymer Letters. 8(11), pp. 791-808. 2014 DOI: $10.3144 /$ expresspolymlett.2014.82

[6] Siengchin, S., Dangtungee, R. "Effect of woven flax structures on morphology and properties of reinforced modified polylactide composites." Journal of Thermoplastic Composite Materials. 26(10), pp. 1424-1440. 2013. DOI: $10.1177 / 0892705712475005$

[7] Reis, K. C., Pereira, J., Smith, A. C., Carvalho, C. W. P., Wellner, N., Yakimets, I. "Characterization of polyhydroxybutyrate-hydroxyvalerate (PHB-HV)/maize starch blend films." Journal of Food Engineering. 89(4), pp. 361-369. DOI: 10.1016/j.jfoodeng.2008.04.022

[8] Singh, S., Mohanty, A. K., Sugie, T., Takai, Y., Hamada, H. "Renewable resource based biocomposites from natural fiber and polyhydroxybutyrate-covalerate (PHBV) bioplastic." Composites Part A: Applied Science and Manufacturing. 39(5), pp. 875-886. 2008. DOI: 10.1016/j.compositesa.2008.01.004

[9] Dangtungee, R., Tengsuthiwat, J., Boonyasopon, P., Siengchin, S. "Sisal natural fiber/clay-reinforced poly(hydroxybutyrate-co-hydroxyvalerate) hybrid composites." Journal of Thermoplastic Composite Materials. 28(6), pp. 879-895. 2014. DOI: 10.1177/0892705714563128

[10] Li, X., Tabil, L. G., Panigrahi, S. "Chemical Treatments of Natural Fiber for Use in Natural Fiber-Reinforced Composites: A Review." Journal of Polymers and the Environment. 15(1), pp. 25-33. 2007.

DOI: 10.1007/s10924-006-0042-3

[11] Puitel, A. C., Tofanica, B. M., Gavrilescu, D., Petrea, P. V. "Environmentally sound vegetal fiber-polymer matrix composites." Cellulose Chemistry and Technology. 45(3-4), pp. 265-274. 2011.

[12] Siengchin, S., Pohl, T., Medina, L., Mitschang, P. "Structure and properties of flax/polylactide/alumina nanocomposites." Journal of Reinforced Plastics and Composites. 32(1), pp. 23-33. 2013. DOI: 10.1177/0731684412464586

[13] Teo, P. S., Chow, W. S. "Water vapour permeability of poly (lactic acid)/ chitosan binary and ternary blends." KMUTNB: International Journal of Applied Science and Technology. 7(1), pp. 23-27. 2014.

DOI: 10.14416/j.ijast.2014.01.001

[14] Becker, O., Varley, R. J., Simon, G. P. "Thermal stability and water uptake of high performance epoxy layered silicate nanocomposites." European Polymer Journal. 40(1), pp. 187-195. 2004. DOI:10.1016/j.eurpolymj.2003.09.008

[15] Lee, S., Kang, I., Doh, G., Kim, W., Kim, J., Yoon, H., Wu, Q. "Thermal, mechanical and morphological properties of polypropylene/clay/wood flour nanocomposites." Express Polymer Letters. 2(2), pp. 78-87. 2008. DOI: 10.3144/expresspolymlett.2008.11

[16] Ndiaye, D., Diop, B., Thiandoume, C., Fall, P. A., Farota, A. K., Tidjani, A. "Morphology and Thermo Mechanical Properties of Wood/Polypropylene Composites." In: Polypropylene. (Dogan, F. (ed.)), Chapter 22, InTech, Rijeka, Croatia, pp. 415-428. 2012. DOI: 10.5772/36148 